\title{
Impact of breast cancer family history on tumor detection and tumor size in women newly-diagnosed with invasive breast cancer
}

\author{
Fabienne Dominique Schwab • Nicole Bürki • Dorothy Jane Huang • \\ Viola Heinzelmann-Schwarz • Seraina Margaretha Schmid • \\ Marcus Vetter • Andreas Schötzau • Uwe Güth
}

Published online: 4 September 2013

(C) Springer Science+Business Media Dordrecht 2013

\begin{abstract}
This study evaluated the impact of family history $(\mathrm{FH})$ on tumor detection, the patient's age and tumor size at diagnosis in breast cancer (BC). Furthermore, we investigated whether the impact of $\mathrm{FH}$ on these features was dependent on degree of relationship, number of relatives with a BC history, or the age of the affected relative at the time that her BC was diagnosed. Out of the entire cohort $(\mathrm{n}=1,037), 244$ patients $(23.5 \%)$ had a positive FH; 159 (15.3\%) had first-degree relatives affected with $\mathrm{BC}$ and 85 patients $(8.2 \%)$ had second-degree affected relatives. Compared to women who had no BC-affected relatives, the tumors of women who had positive $\mathrm{FH}$ were more often found by radiological breast examination (RBE: $31.7 \% / 27.2 \%, p=0.008$ ), and they were smaller (general tumor size: $21.8 \mathrm{~mm} / 26.4 \mathrm{~mm}, p=0.003$; size of tumors found by breast self-examination (BSE): $26.1 \mathrm{~mm} /$ $30.6 \mathrm{~mm}, p=0.041)$. However, this positive effect of increased use of BC screening and smaller tumor sizes was only observed in patients whose first-degree relatives were affected (comparison with second-degree affected
\end{abstract}

F. D. Schwab - D. J. Huang - V. Heinzelmann-Schwarz ·

U. Güth

Department of Gynecology and Obstetrics, University Hospital

Basel (UHB), Spitalstrasse 21, 4031 Basel, Switzerland

N. Bürki

Department of Gynecology and Obstetrics, Cantonal Hospital

Baselland, Rheinstrasse 26, 4410 Liestal, Switzerland

S. M. Schmid

Department of Gynecology and Obstetrics, Spital Grabs,

Spitalstrasse 44, 9472 Grabs, Switzerland

M. Vetter

Department of Oncology, UHB, Petersgraben 4, 4031 Basel,

Switzerland relatives: RBE: $43.8 \% / 24.7 \%$; odds ratio 2.38 , $p=0.007$; general tumor size: $19.3 \mathrm{~mm} / 26.3 \mathrm{~mm}$; mean difference (MD) $-6.9, p=0.025$; tumor size found by BSE: $22.5 \mathrm{~mm} / 31.0 \mathrm{~mm}$; MD $-8.5, p=0.044)$. When more second-degree relatives or older relatives were diagnosed with $\mathrm{BC}$, the tumors of these patients were similarly often detected by RBE (relationship: $24.7 \%$ / $27.2 \%, p=0.641$; age: $33.7 \% / 27.2 \%, p=0.177)$ and had similar tumor sizes (general size: $26.3 \mathrm{~mm} / 26.4 \mathrm{~mm}$, $p=0.960$; BSE: $31.0 \mathrm{~mm} / 30.6 \mathrm{~mm}, p=0.902)$ as those of women without a FH. Women with a positive FH generally use mammography screening more often and perceive changes in the breast earlier than women without such history. The increased awareness of BC risk decreases if the relationship is more distant.

Keywords Breast cancer - Family history · Detection method $\cdot$ Mammography screening $\cdot$ Breast self-examination · Tumor size

\footnotetext{
A. Schötzau

Eudox Institute for Biomathematics, Malzgasse 9, 4052 Basel, Switzerland

U. Güth $(\square)$

Department of Gynecology and Obstetrics, Cantonal Hospital Winterthur, Brauerstrasse 15, 8401 Winterthur, Switzerland e-mail: uwe.gueth@unibas.ch

U. Güth

Breast Center "SenoSuisse", Brauerstrasse 15, 8401 Winterthur, Switzerland
} 


\section{Introduction}

It is widely recognized that a woman's risk of developing breast cancer (BC) is increased if she has a family history $(\mathrm{FH})$ of the disease $[1,2]$. In Western countries, the lifetime excess incidence of $\mathrm{BC}$ is $5.5 \%$ for women with one affected first-degree relative and $13.3 \%$ for women with two [1].

This study evaluates to what extent established radiological screening methods for BC detection were utilized in $\mathrm{BC}$ patients with a positive $\mathrm{FH}$, compared to women without affected relatives. The increased frequency of radiological examinations in women with a positive $\mathrm{FH}$ might demonstrate how personal and familial experiences with BC can influence individuals' behaviors, thus leading to earlier detection of the disease [2-6]. Furthermore, the impact of FH on the patient's age at diagnosis and tumor size at diagnosis was analyzed. As a next step, we investigated whether the impact of FH on tumor detection, patient's age and tumor size was dependent on factors such as degree of relationship (first-degree vs. second-degree), number of relatives with a history of $\mathrm{BC}(1 \mathrm{vs} . \geq 1)$, or the age of the affected relative at the time that her BC was diagnosed ( $<50$ vs. $\geq 50$ years).

During the last decade, there have only been a few studies which evaluated the impact of $\mathrm{FH}$ on $\mathrm{BC}$ detection and tumor size in BC patient cohorts [7-9]. To our knowledge, our study is the first comprehensive analysis of the impact of $\mathrm{FH}$ on $\mathrm{BC}$ detection and tumor size based on a more recent population-based cohort (1990-2009) which does not exclusively consider a subgroup of younger BC patients [8], but rather also analyzes women at an age in which BC mainly occurs (women up to and including 70 years of age).

\section{Patients and methods}

Data from the prospective relational Basel Breast Cancer Database (BBCD), which includes all newly diagnosed primary invasive $\mathrm{BC}$ cases treated at the University Women's Hospital Basel, Switzerland since 1990 provided the basis for this study. This institution comprises the largest $\mathrm{BC}$ center in the canton of Basel and is an adequate representation of the regional population. Within this database, disease-specific clinical and histopathological data, treatment characteristics, personal and family history as well as outcome data was recorded. For this study, data from female patients up to and including 2009, who were $\leq 70$ years at diagnosis, was analyzed $(n=1,056)$. Since the goal of the study was to evaluate the impact of FH on tumor detection method and tumor size, 19 cases with inflammatory BC were excluded from further analysis. Due to the nature of inflammatory carcinomas, which arise rapidly, affect large parts of the breast, and often have no underlying definable mass, these cases are not suitable for evaluating tumor detection methods and tumor size. In total, our study cohort comprised 1,037 patients.

\section{Family history}

The criterion for a positive $\mathrm{FH}$ of $\mathrm{BC}$ was met when a patient reported:

- one or more first-degree (mother, sister, daughter) affected relatives, $\mathrm{n}=159$,

- one or more second-degree (aunt, grandmother) affected relatives, $\mathrm{n}=107$.

In 22 cases, the patients had both first-degree and second-degree affected relatives; we placed these patients in the "first-degree relative"-category, leading to 85 patients being placed in the "second-degree relative"-category.

For patients with a positive $\mathrm{FH}$ of $\mathrm{BC}$, the number of $\mathrm{BC}$ affected relatives and their age at diagnosis $(<50$ vs. $\geq 50$ years) was evaluated. Thirteen cases (first-degree relatives, $\mathrm{n}=10$, second-degree relatives, $\mathrm{n}=3$ ), in which two or more relatives had been diagnosed in both the younger and older ages, were considered as " $<50$ years" only.

\section{Clinicopathological data}

The following data was available for all patients: age at initial diagnosis, histological subtype, grading, hormonal receptor (HR) status, tumor stage according to the American Joint Committee on Cancer (AJCC)/International Union Against Cancer (UICC) TNM Classification [10, 11]. Because HER-2 status has been routinely assessed for all patients since 2002, we included data from 2002-2009 only in the analysis of this particular characteristic. Carcinomas of the triple negative subtype are characterized by a lack of expression of the estrogen receptor, progesterone receptor, and HER2.

\section{Tumor size}

For most of our patients $(\mathrm{n}=976,94.1 \%)$, the size of the primary tumor was measured during pathological examination of the surgically resected lesion. In 40 patients (3.9 \%; positive FH: $\mathrm{n}=8$, negative FH: $\mathrm{n}=32$ ), where neoadjuvant therapy was given, the pre-therapeutic clinically assessed tumor sizes were used. The same was the case for 21 patients $(2.0 \%$; positive $\mathrm{FH}: \mathrm{n}=3$; negative FH: $n=19$ ), where no surgery was performed. 
Of the entire study cohort, 20 patients presented with synchronous bilateral BC (1.9\%); of these cases, the tumor with the more advanced tumor size ("reference lesion") was considered for analysis.

\section{Tumor detection method}

The following two main methods were analyzed:

1. breast self-examination (BSE), $\mathrm{n}=600(57.9 \%)$

2. radiological breast examination (RBE), $\mathrm{n}=253$ $(24.4 \%)$

Cases in which the tumor was found by a physician during a clinical breast examination [CBE, $\mathrm{n}=151$ $(14.6 \%)$ ] were not considered in the diagnostic method analysis, because, contrary to BSE and the utilization of RBE, CBE does not necessarily reflect the patient's awareness of early $\mathrm{BC}$ detection. The following patients were also excluded from this part of analysis: 13 patients $(1.2 \%)$, in which other detection modes apart from the ones mentioned above were used, and 20 patients $(1.9 \%)$, in which the method of tumor detection was not reported in the clinical files.

Data collection methods and study design were approved by the Ethics Committee of the University of Basel.

\section{Statistical methods}

Comparisons between nominal parameters were made using the Fisher exact test. In the case of the dependent variables age and tumor size, univariate linear regression analysis was performed. Results are presented as differences of means (MD) with corresponding $95 \%$ confidence intervals (95\% CI) and $p$ values. In the case of the binary dependent variable (detection method), logistic regressions were performed. Results are presented as odds ratios (OR) with the corresponding $95 \% \mathrm{CI}$ and $p$ values. In all statistical tests the level of significance was $p<0.05$. All evaluations were performed with $\mathrm{R}$ Development Core Team software, version 13.1. The study is exploratory; therefore, no adjustments for multiple comparisons were done.

\section{Results}

Out of the entire cohort $(\mathrm{n}=1,037), 244$ patients $(23.5 \%)$ had a positive $\mathrm{FH}$ for BC. Of these, 159 (15.3\%) had firstdegree relatives affected by $\mathrm{BC}$ and 85 patients $(8.2 \%)$ had second-degree affected relatives only. Table 1 lists the number of relatives with a history of $\mathrm{BC}$ and the age group of the affected relative at the time that her $\mathrm{BC}$ was diagnosed.

Pathological characteristics (Table 2)

Comparing the incidence of histological subtypes, there were more lobular carcinomas in patients with a positive $\mathrm{FH}$ than in those without FH (16.9 vs. $11.7 \%, p=0.037$ ). Patients with a positive FH showed less commonly established indicators of tumor aggressiveness such as poorly differentiated carcinomas (G3: 33.9 vs. $46.6 \%$, $p<0.001)$, a negative HR-negative status (13.5 vs. $19.2 \%, p=0.052)$ and triple-negative subtype (6.5 vs. $13.6 \%, p=0.007)$.

Age at diagnosis (Tables 2 and 3)

There was no significant difference between patients with and without $\mathrm{FH}$ with respect to age at diagnosis (53.8 vs. 54.8 years, $p=0.201$ ). However, patients with a positive $\mathrm{FH}$, who had only second-degree BC affected relatives, were significantly younger when compared with patients who had no FH (51.2 vs. 54.8 years, MD -3.6 years, $95 \%$ CI -5.9 to $-1.3, p=0.002$ ), as well as patients with a positive $\mathrm{FH}$ and first-degree $\mathrm{BC}$ affected relatives (51.2 vs. 55.2 years, $\mathrm{MD}-4.0$ years, $95 \% \mathrm{CI}-6.7$ to -1.2 , $p=0.004)$. There was a similar age distribution in patients with no FH and those who had a positive FH with firstdegree BC affected relatives (54.8 vs. 55.2 years, $p=0.652$ ).

Patients whose relatives were diagnosed with $\mathrm{BC}$ at a younger age $(<50$ years) were themselves significantly younger at diagnosis than patients with negative $\mathrm{FH}$ (51.7 vs. 54.8 years, $\mathrm{MD}-3.1$ years, $95 \% \mathrm{CI}-5.4$ to -0.7 , $p=0.009$ ) and patients with a positive $\mathrm{FH}$ whose relatives were diagnosed with $\mathrm{BC}$ at an older age (51.7 vs. 56.1 years, MD -4.4 years, $95 \%$ CI -7.3 to -1.6 , $p=0.002$ ). Hereby, the number of affected relatives was not found to have a substantial impact upon age at diagnosis $(p=0.440)$.

Tumor detection method: radiological breast examination versus self-examination (Table 2 and 4)

Compared to the tumors of patients without FH, the lesions of patients who had a positive $\mathrm{FH}$ were more often found by $\operatorname{RBE}(37.1$ vs. $27.2 \%, p=0.008)$. Within the group of patients with a positive $\mathrm{FH}$ the tumors were significantly more often found by RBE in patients with first-degree BC affected relatives than in those with second-degree affected relatives (43.8 vs. $24.7 \%$; OR 2.38, $95 \%$ CI 1.27-4.54, $p=0.007)$. In patients with a positive $\mathrm{FH}$ who had only second-degree BC affected relatives, the tumors were 
Table 1 Breast cancer patients ( $\leq 70$ years) with positive $\mathrm{FH}$ of BC $(n=244)$ : Degree of relationship, number of affected relatives, and age of the affected relative at the time that her $\mathrm{BC}$ was diagnosed

\begin{tabular}{ll}
\hline Characteristic & $\mathrm{n}(\%)$ \\
\hline First-degree relatives & $159(65.2)$ \\
Second-degree relatives & $85(34.8)$ \\
First-degree relatives & 159 \\
Relative diagnosed before age 501 & $70(44.0)$ \\
Relative diagnosed $\geq 50$ years & \\
Relative's age unknown & $88(55.4)$ \\
One family member affected with BC & $1(0.6)$ \\
Two family members affected with BC & $141(88.7)$ \\
Three family members affected with BC & $17(10.7)$ \\
Mean number & $1(0.6)$ \\
Second-degree relatives & 1.1 \\
Relative diagnosed before age 50 & 85 \\
Relative diagnosed $\geq 50$ years & $10(11.8)$ \\
Relative's age unknown & $38(44.7)$ \\
One family member affected with BC & $37(43.5)$ \\
Two family members affected with BC & $68(80.0)$ \\
Three family members affected with BC & $13(15.3)$ \\
Four family members affected with BC & $3(3.5)$ \\
Mean number & $1(1.2)$ \\
Entire group of patients with positive FH (first degree and second-degree relatives) & 1.3 \\
One family member affected with BC & 244 \\
Two family members affected with BC & $188(77.1)$ \\
Three family members affected with BC & $43(17.6)$ \\
Four family members affected with BC & $11(4.5)$ \\
Mean number & $2(0.8)$ \\
\hline
\end{tabular}

$B C$ breast cancer, $F H$ family history

${ }^{1}$ In one case, FH showed that the father of the patient had been diagnosed with $\mathrm{BC}$ at the age of 80 years; in a second case, one/a brother of the patient was diagnosed at the age of 38 years. According to the age segments, these cases were considered as " $<50$ years" (brother) and " $\geq 50$ years" (father) found just as often by $\mathrm{RBE}$ as in patients without $\mathrm{FH}(24.7$ vs. $27.2 \%, p=0.641$ ).

In patients whose relatives were $<50$ years of age at their BC diagnosis, we found that the tumors tended to be more often found by $\mathrm{RBE}$ compared to patients whose relatives were diagnosed with $\mathrm{BC}$ at an older age (47.3 vs. $33.7 \%$; OR 1.79 , $95 \%$ CI 1.00-3.23, $p=0.067$; comparison with patients without $\mathrm{FH}: 47.3$ vs. $27.2 \%$; OR $2.40,95 \%$ CI $1.47-3.90, p<0.001)$. In patients whose relatives were diagnosed with $\mathrm{BC}$ at a more advanced age ( $\geq 50$ years), this observation was not made (33.7 vs. $27.2 \%, p=0.177)$. The number of the affected relatives was not relevant $(p=0.158)$.

Tumor size (Table 2 and 5)

Compared to patients without $\mathrm{FH}$, patients with a positive $\mathrm{FH}$ had smaller tumors at diagnosis $(21.8$ vs. $26.4 \mathrm{~mm}$, $p=0.003$ ). Within the group of patients with a positive $\mathrm{FH}$, patients with first-degree $\mathrm{BC}$ affected relatives had smaller tumors than those with second-degree affected relatives (19.3 vs. $26.3 \mathrm{~mm}$; MD $-6.9,95 \% \mathrm{CI}-13.0$ to $-0.9, p=0.025)$. The tumor sizes of patients with a positive $\mathrm{FH}$ who had only second-degree $\mathrm{BC}$ affected relatives were similar to those of patients without a $\mathrm{FH}$ (26.3 vs. $26.4 \mathrm{~mm}, p=0.960$ ). Within the group of patients with positive $\mathrm{FH}$, the age at which the affected relative was diagnosed with $\mathrm{BC}$ did not correlate with tumor size ( $<50$ years: $18.4 \mathrm{~mm}$ vs. $\geq 50$ years: $21.0 \mathrm{~mm}$, $p=0.403)$.

We found similar results for the subgroup of patients who found their tumors by BSE. Compared to patients without $\mathrm{FH}$, patients with positive $\mathrm{FH}$ found smaller lesions (26.1 vs. $30.6 \mathrm{~mm}, p=0.041)$. Patients with firstdegree $\mathrm{BC}$ affected relatives found their tumors at smaller sizes than patients who had only second-degree $\mathrm{BC}$ affected relatives $(22.5$ vs. $31.0 \mathrm{~mm}$; $\mathrm{MD}-8.5,95 \% \mathrm{CI}$ -17.6 to $-0.6, p=0.044)$ and patients without $\mathrm{FH}$ (22.5 vs. $30.6 \mathrm{~mm}$; $\mathrm{MD}-8.1,95 \% \mathrm{CI}-14.4$ to $-1.7, p=0.013)$. Patients with positive $\mathrm{FH}$ and only second-degree $\mathrm{BC}$ affected relatives identified their tumors at a similar size as those with negative FH (31.0 vs. $30.6 \mathrm{~mm}, p=0.902)$. Within the group of patients with positive $\mathrm{FH}$, the age at which the affected relative was diagnosed with $\mathrm{BC}$ was not significantly correlated with tumor size ( $<50$ years: $23.9 \mathrm{~mm}$ vs. $\geq 50$ years: $22.9 \mathrm{~mm}, p=0.841)$. 
Table 2 Comparison between a cohort of 1,037 BC patients ( $\leq 70$ years) with and without $\mathrm{FH}$ of $\mathrm{BC}$
AJCC American Joint

Committee on Cancer, UICC

International Union Against

Cancer $[10,11]$

Statistically significant data (the level of significance $p<0.05$ ) are highlighted in bold

\begin{tabular}{|c|c|c|c|}
\hline Variable & $\begin{array}{l}\text { Family history (positive) } \\
\mathrm{n}=244\end{array}$ & $\begin{array}{l}\text { Family history (negative) } \\
\mathrm{n}=793(\%)\end{array}$ & $p$ value \\
\hline \multicolumn{4}{|l|}{ Age (years) } \\
\hline Mean & 53.8 & 54.8 & 0.201 \\
\hline Median & 54 & 56 & \\
\hline \multicolumn{4}{|l|}{ Tumor detection method } \\
\hline Breast self-examination & $132(54.1)$ & $468(59.0)$ & \\
\hline Radiologic examination & $78(32.0)$ & $175(22.1)$ & 0.008 \\
\hline $\begin{array}{l}\text { Clinical breast examination (by } \\
\text { physician) }\end{array}$ & $24(9.8)$ & $127(16.0)$ & \\
\hline Other method & $4(1.6)$ & $9(1.1)$ & \\
\hline Unknown & $6(2.5)$ & $14(1.8)$ & \\
\hline \multicolumn{4}{|l|}{ Tumor size (mm) } \\
\hline Mean & 21.8 & 26.4 & 0.003 \\
\hline Median (range) & $17(0.5-220)$ & $20(0-210)$ & \\
\hline \multicolumn{4}{|l|}{ Tumor category } \\
\hline T0 & 0 & $2(0.2)$ & $<0.001$ \\
\hline $\mathrm{T} 1$ & $159(65.1)$ & $405(51.1)$ & \\
\hline $\mathrm{T} 2$ & $68(27.9)$ & $296(37.3)$ & \\
\hline $\mathrm{T} 3$ & $10(4.1)$ & $61(7.7)$ & $\begin{array}{r}\mathrm{T} 3 / \mathrm{T} 4: \\
0.054\end{array}$ \\
\hline Non-inflammatory T4 & $7(2.9)$ & $29(3.7)$ & \\
\hline Bilateral synchronous carcinoma & $5(2.1)$ & $15(1.9)$ & 0.80 \\
\hline \multicolumn{4}{|l|}{ AJCC/UICC TNM stage } \\
\hline I & $119(48.8)$ & $284(35.8)$ & $<0.001$ \\
\hline II & $82(33.6)$ & $324(40.9)$ & \\
\hline III & $37(15.2)$ & $142(17.9)$ & \\
\hline IV & $6(2.4)$ & $43(5.4)$ & 0.059 \\
\hline \multicolumn{4}{|l|}{ Histologic subtype } \\
\hline Ductal invasive & $171(70.7)$ & $609(77.3)$ & \\
\hline Lobular invasive & $41(16.9)$ & $92(11.7)$ & 0.037 \\
\hline Rare types & $30(12.4)$ & $87(11.0)$ & \\
\hline Not available & 2 & 5 & \\
\hline \multicolumn{4}{|l|}{ Grading } \\
\hline $\mathrm{G} 1 / 2$ & $154(66.1)$ & $400(53.4)$ & \\
\hline G3 & 79 (33.9) & 349 (46.6) & $<0.001$ \\
\hline Not available & 11 & 44 & \\
\hline \multicolumn{4}{|l|}{ Hormonal receptor status } \\
\hline Positive & $205(86.5)$ & $614(80.8)$ & 0.052 \\
\hline Negative & $32(13.5)$ & $146(19.2)$ & \\
\hline Not available & 7 & 33 & \\
\hline HER2 status, 2002-2009 & $\mathrm{n}=124(\%)$ & $\mathrm{n}=339(\%)$ & \\
\hline Positive & $19(15.4)$ & $61(18.1)$ & 0.57 \\
\hline Not available & 1 & 2 & \\
\hline Triple-negative subtype & $8(6.5)$ & 46 (13.6) & 0.007 \\
\hline
\end{tabular}

analyzed 52 epidemiological studies in which 58,209 BC patients were analyzed. The results of this large data collection are approximately comparable with our data (15.3\% of the BC patients had first-degree relatives affected by BC). 
Table 3 Patient's age according to FH of BC

\begin{tabular}{|c|c|c|}
\hline & $\mathrm{MD}(95 \% \mathrm{CI})$ & $p$ value \\
\hline \multicolumn{3}{|c|}{ Degree of relationship } \\
\hline \multicolumn{3}{|c|}{ 0. no FH: 54.8 years } \\
\hline \multicolumn{3}{|c|}{ 1. First-degree FH: 55.2 years } \\
\hline \multicolumn{3}{|c|}{ 2. Second-degree FH: 51.2 years } \\
\hline Overall & & 0.007 \\
\hline 1 versus 0 & $0.4(-1.4,2.2)$ & 0.652 \\
\hline 2 versus 0 & $-3.6(-5.9,-1.3)$ & 0.002 \\
\hline 2 versus 1 & $-4.0(-6.7,-1.2)$ & 0.004 \\
\hline \multicolumn{3}{|c|}{ Number of affected relatives } \\
\hline Overall & & 0.322 \\
\hline \multicolumn{3}{|c|}{1 affected relative: 53.5 years } \\
\hline \multicolumn{3}{|c|}{$\geq 1$ affected relative: 54.8 years } \\
\hline 1 versus $\geq 1$ & $1.2(-1.9,4.3)$ & 0.440 \\
\hline \multicolumn{3}{|c|}{ Age of the affected relative at the time that her $\mathrm{BC}$ was diagnosed } \\
\hline \multicolumn{3}{|c|}{ 0. no FH: 54.8 years } \\
\hline \multicolumn{3}{|c|}{ 1. $\mathrm{FH},<50$ years: 51.7 years } \\
\hline \multicolumn{3}{|c|}{ 2. $\mathrm{FH}, \geq 50$ years: 56.1 years } \\
\hline Overall & & 0.008 \\
\hline 1 versus 0 & $-3.1(-5.4,-0.8)$ & 0.009 \\
\hline 2 versus 0 & $1.3(-0.6,3.3)$ & 0.175 \\
\hline 1 versus 2 & $-4.4(-7.3,-1.6)$ & 0.002 \\
\hline
\end{tabular}

$M D$ mean difference, $C I$ confidence interval, $F H$ family history, $B C$ breast cancer

Statistically significant data (the level of significance $p<0.05$ ) are highlighted in bold

Our study confirms previously published data [8], which demonstrated that in a cohort of $\mathrm{BC}$ patients, the tumors of women who had a positive $\mathrm{FH}$ for $\mathrm{BC}$ were more often found by RBE compared to women who had no BC affected relatives. This might result from the fact that women with a family BC history, obviously influenced by personal and familial experiences with $\mathrm{BC}$, generally use $\mathrm{BC}$ screening more often than women without such history [2-6]. It is not possible to determine precisely to what extent the higher motivation for mammography can be attributed to the women's own initiative, the direct influence of family members (e.g. mother-daughter communication) or the motivating influence of their doctors who are aware of the positive FH and incorporate this information into their mammography referral practices. However, this positive effect of increased use of and adherence to BC screening is essentially due to a particular subgroup of patients with positive $\mathrm{FH}$, namely those whose first-degree relatives were affected and those whose relatives were diagnosed with $\mathrm{BC}$ at an earlier age ( $<50$ years). When more distantly related relatives (second-degree relatives) or older relatives ( $\geq 50$ years of age) were diagnosed with $\mathrm{BC}$, the motivation to have $\mathrm{BC}$ screening could not be positively influenced. The tumors of these patients were similarly often detected by RBE as those of women without FH.
Table 4 Tumor detection method (radiological breast examination vs. self-examination) according to $\mathrm{FH}$ of $\mathrm{BC}$

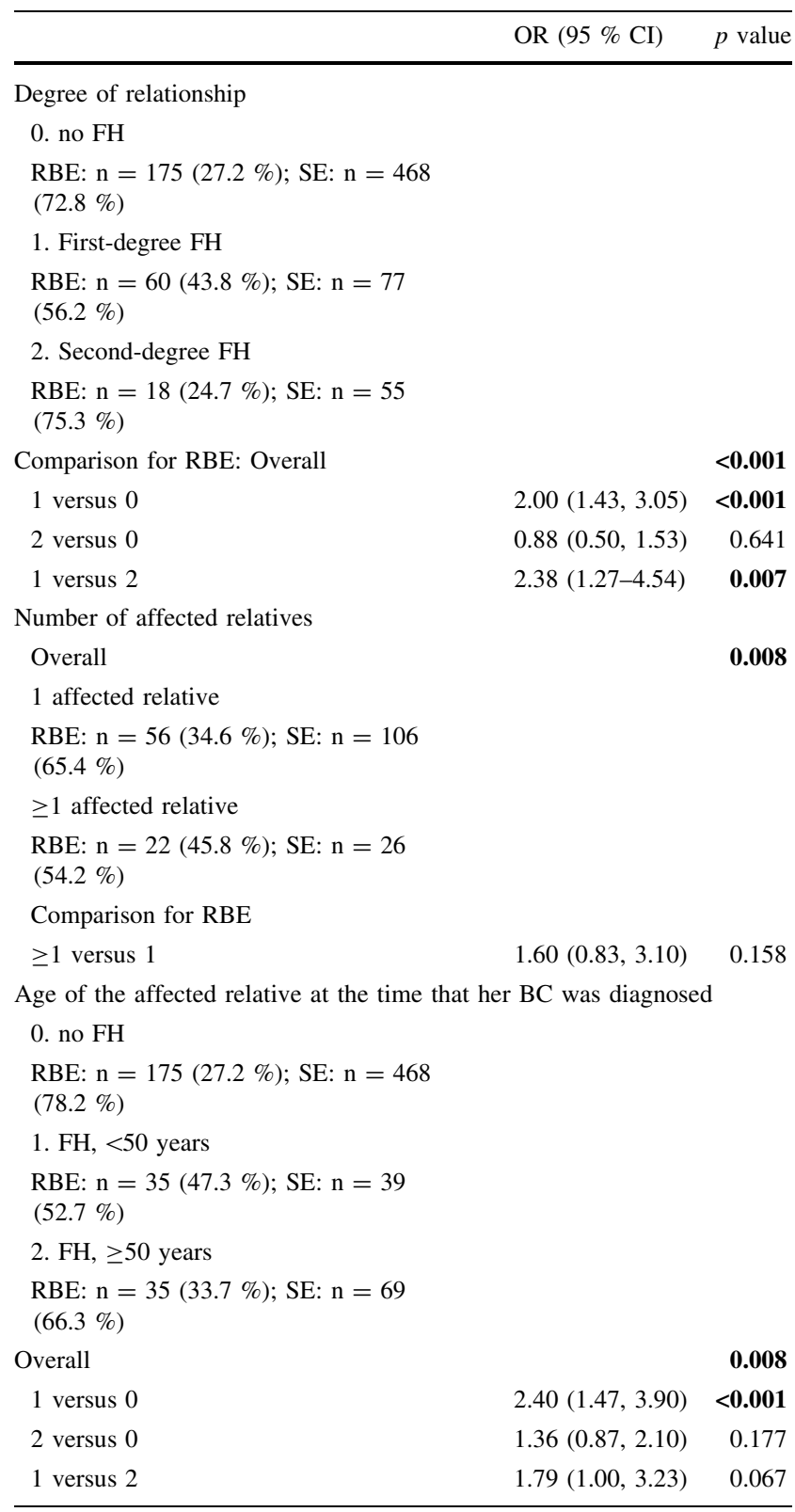

$O R$ odds ratio, $C I$ confidence interval, $F H$ family history, $B C$ breast cancer, $R B E$ radiological breast examination, $S E$ self examination

Statistically significant data (the level of significance $p<0.05$ ) are highlighted in bold

We observed a similar pattern in the analysis of tumor size. The tumors of patients with positive $\mathrm{FH}$ for $\mathrm{BC}$ were significantly smaller compared to tumors of patients with negative $\mathrm{FH}$ and, again, this positive effect was primarily determined by the patients with first-degree BC affected relatives. In contrast, patients who had only second-degree BC affected relatives had similar tumor sizes to patients without a FH for BC. These findings are consistent with those of Tracy et al. [6], who also showed that the degree of 
Table 5 Tumor size according to FH of BC. I. All patients; II. Tumors found by self-examination

\begin{tabular}{|c|c|c|}
\hline & $\mathrm{MD}(95 \% \mathrm{CI})$ & $p$ value \\
\hline \multicolumn{3}{|l|}{ All patients } \\
\hline \multicolumn{3}{|c|}{ Degree of relationship } \\
\hline \multicolumn{3}{|c|}{ 0. no FH: $26.4 \mathrm{~mm}$} \\
\hline \multicolumn{3}{|c|}{ 1. First-degree FH: $19.3 \mathrm{~mm}$} \\
\hline \multicolumn{3}{|c|}{ 2. Second-degree FH: $26.3 \mathrm{~mm}$} \\
\hline Overall & & 0.001 \\
\hline 1 versus 0 & $-7.1(-11.0,-3.2)$ & $<0.001$ \\
\hline 2 versus 0 & $-0.1(-5.3,5.0)$ & 0.960 \\
\hline 1 versus 2 & $-6.9(-13.0,-0.9)$ & 0.025 \\
\hline \multicolumn{3}{|c|}{ Number of affected relatives } \\
\hline Overall & & $\mathbf{0 . 0 1 9}$ \\
\hline \multicolumn{3}{|c|}{1 affected relative: $21.3 \mathrm{~mm}$} \\
\hline \multicolumn{3}{|c|}{$\geq 1$ affected relative: $23.4 \mathrm{~mm}$} \\
\hline$\geq 1$ versus 1 & $2.2(-4.7,9.1)$ & 0.535 \\
\hline \multicolumn{3}{|c|}{ Age of the affected relative at the time that her $\mathrm{BC}$ was diagnosed } \\
\hline \multicolumn{3}{|c|}{ 0. no FH: $26.4 \mathrm{~mm}$} \\
\hline \multicolumn{3}{|c|}{ 1. $\mathrm{FH},<50$ years: $18.4 \mathrm{~mm}$} \\
\hline \multicolumn{3}{|c|}{ 2. $\mathrm{FH}, \geq 50$ years: $21.0 \mathrm{~mm}$} \\
\hline Overall & & 0.001 \\
\hline 1 versus 0 & $-8.0(-13.1,-3.0)$ & 0.002 \\
\hline 2 versus 0 & $-5.4(-9.6,-1.1)$ & 0.013 \\
\hline 1 versus 2 & $-2.7(-3.6,8.9)$ & 0.403 \\
\hline \multicolumn{3}{|c|}{ II. Tumors found by self-examination } \\
\hline \multicolumn{3}{|c|}{ Degree of relationship } \\
\hline \multicolumn{3}{|c|}{ 0. no FH: $30.6 \mathrm{~mm}$} \\
\hline \multicolumn{3}{|c|}{ 1. First-degree FH: $22.5 \mathrm{~mm}$} \\
\hline \multicolumn{3}{|c|}{ 2. Second-degree FH: $31.0 \mathrm{~mm}$} \\
\hline Overall & & 0.041 \\
\hline 1 versus 0 & $-8.1(-14.4,-1.7)$ & $\mathbf{0 . 0 1 3}$ \\
\hline 2 versus 0 & $0.5(-6.9,7.8)$ & 0.902 \\
\hline 1 versus 2 & $-8.5(-17.6,-0.6)$ & 0.044 \\
\hline \multicolumn{3}{|c|}{ Number of affected relatives } \\
\hline Overall & & 0.082 \\
\hline \multicolumn{3}{|c|}{1 affected relative: $24.5 \mathrm{~mm}$} \\
\hline \multicolumn{3}{|c|}{$\geq 1$ affected relative: $32.5 \mathrm{~mm}$} \\
\hline$\geq 1$ versus 1 & $8.1(-3.2,19.3)$ & 0.160 \\
\hline \multicolumn{3}{|c|}{ Age of the affected relative at the time that her $\mathrm{BC}$ was diagnosed } \\
\hline \multicolumn{3}{|c|}{ 0. no FH: $30.6 \mathrm{~mm}$} \\
\hline \multicolumn{3}{|c|}{ 1. $\mathrm{FH},<50$ years: $23.9 \mathrm{~mm}$} \\
\hline \multicolumn{3}{|c|}{ 2. $\mathrm{FH}, \geq 50$ years: $22.9 \mathrm{~mm}$} \\
\hline Overall & & $\mathbf{0 . 0 2 6}$ \\
\hline 1 versus 0 & $-6.6(-15.0,1.6)$ & 0.114 \\
\hline 2 versus 0 & $-7.6(-14.0,-1.3)$ & 0.019 \\
\hline 1 versus 2 & $1.0(-8.9,11.0)$ & 0.841 \\
\hline
\end{tabular}

$M D$ mean difference, $C I$ confidence interval, $F H$ family history, $B C$ breast cancer

Statistically significant data (the level of significance $p<0.05$ ) are highlighted in bold relationship between relatives with $\mathrm{BC}$ affected the likelihood of using BC screening. Furthermore, the authors found that $\mathrm{BC}$ death in a family is a stronger predictor for the use of $\mathrm{BC}$ screening.

Our results confirm the findings of recent studies, which showed that women with affected first-degree relatives were more likely to have smaller carcinomas and more often early disease stage [7-9]. Furthermore, our study confirms data from other studies which showed no significant differences with regard to tumor size and stage between patients who had only second-degree relatives affected with $\mathrm{BC}$ and patients without $\mathrm{FH}$ for BC [7, 8].

The phenomenon that patients with a first-degree $\mathrm{BC}$ affected relative had smaller tumors at diagnosis might be explained by more diligent use of BC screening amongst women who considered themselves to be at increased risk of developing the disease. However, we also observed this phenomenon in patients who detected their tumors by selfexamination. In these cases, the personal experience of having a close family member with $\mathrm{BC}$ was so influential that they became more aware of the necessity of selfexamination and perceived changes earlier, thus leading to the identification of smaller tumors. Sinicrope et al. [12], who examined communication about $\mathrm{BC}$ prevention between $\mathrm{BC}$ affected mothers and their daughters, found that $\mathrm{BC}$ prevention behaviors were associated with corresponding advice such as to have a mammogram (51\%) and perform BSE (39\%). Interestingly, the increased awareness of $\mathrm{BC}$ risk does not result in a behavioral change to a more preventive lifestyle, such as weight control or reduction of alcohol consumption [13].

The data regarding the relationship between $\mathrm{FH}$ of $\mathrm{BC}$ and tumor characteristics are inconsistent. Some recent studies found that women with a positive $\mathrm{FH}$ had tumors with a generally more favorable prognostic profile [8, 9], while others suggested that the characteristics of $\mathrm{BC}$ in patients with a positive $\mathrm{FH}$ do not differ substantially between those with and without relatives affected by $\mathrm{BC}$ (overview in [3, 8]); further studies showed that $\mathrm{FH}$ was associated with an increased risk of triple negative and HRnegative/HER2-expressing BC [14]. In our study, women with a positive $\mathrm{FH}$ had tumors with more favorable prognostic profiles as assessed by tumor size, disease stage, histologic grading, HR status and triple negative subtype. Malone et al. [8] reported in a recently published study, which examined a population-based cohort of younger BC patients, that those with a first-degree $\mathrm{FH}$, compared with their counterparts without such a FH, had a better prognosis (40\% reduction in the risk of dying). The fact that patients with a positive $\mathrm{FH}$ have $\mathrm{BC}$ screening more often and might have more favorable tumor characteristics, support data which demonstrated a better prognosis for $\mathrm{BC}$ patients with a positive $\mathrm{FH}$. 
There are particular factors which must be considered in the interpretation of our findings. In the canton of Basel and the adjoining region of Northwestern Switzerland, there is no publicly funded organized mammography screening program. All interested and motivated women, however, have free access to mammography. In such an environment, the utilization of RBE for early BC detection is strongly dependent on the women's motivation and own initiative (opportunistic screening) as well as the recommendation by her physician. For the purpose of our study, i.e. to test whether the knowledge and experience of a $\mathrm{BC}$ in the family increases BC awareness, a patient-driven screening setting is better suited than a general screening setting. Furthermore, the referral practice for mammography, particularly in younger women, might be influenced by physicians who are aware of the positive $\mathrm{FH}$ of their patients. However, this motivating impact is hard to assess in individual cases.

In the future, the impact of $\mathrm{FH}$ on $\mathrm{BC}$ screening may become less important due to the broader acceptance and use of general screening programs. Furthermore, in Western countries, the number of potential female relatives who could potentially develop BC is reduced simply through the development of generally smaller, nuclear families.

\section{Strengths and limitations}

During the last decade, there have only been a few studies which evaluated the impact of $\mathrm{FH}$ on $\mathrm{BC}$ detection and tumor size in BC patient cohorts [7-9]. However, most of them reported only data on tumor size and stage [7], or tumor size and pathological/biological features [9] but did not consider tumor detection method. Malone et al. [8] applied a more comprehensive approach and reported both tumor size/stage and detection method. However, the authors, whose findings were in part similar to our study, restricted their analysis to younger patients ( $\leq 45$ years) and did not study a current cohort (they ascertained BC cases diagnosed between 1983 and 1992). To our knowledge, our study is the first comprehensive analysis of the impact of $\mathrm{FH}$ on $\mathrm{BC}$ detection and tumor size based on a more recent population-based cohort (1990-2009), which does not exclusively consider a subgroup of younger BC patients. By analyzing a cohort with a broader age segment, we could demonstrate that the positive effect of first-degree relationship is not only present in younger women (BC patients $\leq 45$ years represent approximately only the youngest $15 \%$ of a Western BC cohort) but also in patients in whom BC is usually diagnosed (the median age of the entire cohort of the BC patients documented in our Swiss database was 61 years; patients $\leq 70$ years of age comprise $73 \%$ of the entire cohort of BC patients). Our findings are strengthened by the ability to consider not only degree of relationship but also to assess the confounding effects of number of affected relatives and the age of the affected relative at the time that her BC was diagnosed. We deliberately did not consider BRCA1/BRCA2 mutation carrier separately. Due to the infrequent nature of BRCA1/BRCA2 mutations, even in women with a first-degree history, these mutations do not play an important role in the general behavior of women regarding mammography screening [8].

The following limitations of our study must be considered. Firstly, our study comes from a single region of a small country with a high socioeconomic status and all inhabitants have universal access to health care. Secondly, our study relies on information obtained by patients ' selfreporting of $\mathrm{FH}$. It is possible that in some cases the patients failed to accurately recall their $\mathrm{FH}$ or the complete FH might not be known to all women. Yoon et al. [15] reported that although $96 \%$ of the respondents of a national survey in the USA believed that their FH information is important for their own health, $<30 \%$ had actively collected such information from relatives. Furthermore, the entire $\mathrm{FH}$ regarding malignant diseases may not always be known, since such topics might either not be discussed or purposely concealed from the rest of the family.

\section{Conclusions}

Women with a first-degree relative affected by $\mathrm{BC}$ or a relative who was diagnosed with $\mathrm{BC}$ at younger age have been sufficiently touched by that experience to prompt them to be more diligent in attending mammography screening, and thus be diagnosed earlier, than someone who has not had this experience. The increased awareness of $\mathrm{BC}$ risk, probably a result of personal experience from a close relative, decreases if the relationship is more distant. In patients who have only second-degree relatives, the tumors are diagnosed similarly often by RBE and are of a similar size compared to BC patients without FH.

Conflict of interest The authors declare that they have no conflict of interest.

\section{References}

1. Collaborative Group on Hormonal Factors in Breast Cancer (2001) Familial breast cancer: collaborative reanalysis of individual data from 52 epidemiological studies including 58,209 women with breast cancer and 101,986 women without the disease. Lancet 358(9291):1389-1399

2. Colditz GA, Kaphingst KA, Hankinson SE, Rosner B (2012) Family history and risk of breast cancer: nurses' health study. Breast Cancer Res Treat 133(3):1097-1104 
3. Couto E, Banks E, Reeves G, Pirie K, Beral V (2008) Family history and breast cancer tumour characteristics in screened women. Int J Cancer 123(12):2950-2954

4. Murabito JM, Evans JC, Larson MG, Kreger BE, Splansky GL, Freund KM, Moskowitz MA, Wilson PW (2001) Family breast cancer history and mammography: Framingham offspring study. Am J Epidemiol 154(10):916-923

5. Taplin S, Anderman C, Grothaus L (1989) Breast cancer risk and participation in mammographic screening. Am J Public Health 79(11):1494-1498

6. Tracy KA, Quillin JM, Wilson DB, Borzelleca J, Jones RM, McClish D, Bowen D, Bodurtha J (2008) The impact of family history of breast cancer and cancer death on women's mammography practices and beliefs. Genet Med 10(8):621-625

7. Lijovic M, Davis SR, Fradkin P, Bradbury J, La China M, Schwarz M, Wolfe R, Farrugia H, Bell RJ (2009) The relationship between knowledge of family history and cancer characteristics at diagnosis in women newly-diagnosed with invasive breast cancer. Fam Cancer 8(4):299-305

8. Malone KE, Daling JR, Doody DR, O'Brien C, Resler A, Ostrander EA, Porter PL (2011) Family history of breast cancer in relation to tumor characteristics and mortality in a populationbased study of young women with invasive breast cancer. Cancer Epidemiol Biomarkers Prev 20(12):2560-2571

9. Molino A, Giovannini M, Pedersini R, Frisinghelli M, Micciolo R, Mandara M, Pavarana M, Cetto GL (2004) Correlations between family history and cancer characteristics in 2256 breast cancer patients. Br J Cancer 91(1):96-98

10. Edge S, Byrd D, Compton C, Fritz A, Greene F, Trotti A (eds) (2009) AJCC cancer staging manual, 7th edn. Springer, New York

11. Sobin L, Gospodarowicz M, Wittekind C (eds) (2009) UICC: TNM classification of malignant tumors, 7th edn. Blackwell, Oxford

12. Sinicrope PS, Brockman TA, Patten CA, Frost MH, Vierkant RA, Petersen LR, Rock E, Clark LP, Vachon CM, Fredericksen ZS et al (2008) Factors associated with breast cancer prevention communication between mothers and daughters. J Womens Health (Larchmt) 17(6):1017-1023

13. Ochoa EM, Gomez-Acebo I, Rodriguez-Cundin P, NavarroCordoba M, Llorca J, Dierssen-Sotos T (2010) Relationship between family history of breast cancer and health-related behavior. Behav Med 36(4):123-129

14. Phipps AI, Buist DS, Malone KE, Barlow WE, Porter PL, Kerlikowske K, Li CI (2011) Family history of breast cancer in firstdegree relatives and triple-negative breast cancer risk. Breast Cancer Res Treat 126(3):671-678

15. Yoon PW, Scheuner MT, Jorgensen C, Khoury MJ (2009) Developing Family Healthware, a family history screening tool to prevent common chronic diseases. Prev Chronic Dis 6(1):A33 